\title{
A guide to curettage and cautery in the management of skin lesions
}

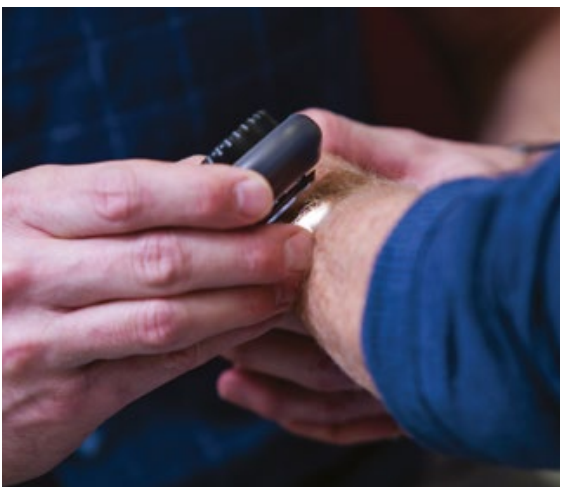

CPD

Daniel Mazzoni, Jim Muir

\section{Background}

Curettage and cautery is a procedure used for treatment of low-risk skin malignancies and pre-cancerous lesions. Given good lesion selection and technique, high cure rates and good cosmesis are routine for this quick, simple and cost-effective operation.

\section{Objective}

The purpose of this article is to review and summarise the steps in managing carefully selected cutaneous lesions with curettage and cautery.

\section{Discussion}

This article will address lesion selection, technique, efficacy, complications and how to incorporate curettage into daily practice.
CURETTAGE AND CAUTERY is a type of electrosurgery used to treat low-risk skin malignancies and pre-cancerous lesions. This procedure is a simple, quick and cost-effective option which, when used appropriately and correctly, has shown excellent clinical efficacy and favourable cosmetic outcomes.

The aim of this article is to address the key aspects of curettage and cautery in the management of cutaneous lesions so that this procedure can be incorporated into daily practice.

A 2006 study found that $62 \%$ of surveyed Australian general practitioners (GPs) never used curettage in basal cell carcinoma (BCC) management. ${ }^{1}$ The Cancer Council of NSW stated in 2020 that:

\section{Curettage and electrodessication (or} cautery) is used to treat some BCCs and squamous cell carcinoma in situ (Bowen's disease). It is usually done by a dermatologist. ${ }^{2}$

Curettage has equal cure rates to excision, cryotherapy or radiation treatment for suitable BCC and squamous cell carcinoma in situ and far outweighs the efficacy of imiquimod and photodynamic therapy. ${ }^{3-8}$ It is also a useful treatment for keratoacanthoma and small, well-differentiated squamous cell carcinoma (SCC). ${ }^{6}$ The procedure is quick, the equipment needed is minimal, and the technique is easily learnt. ${ }^{9}$ As with any procedure, comprehensive training in lesion selection and surgical technique is essential.

\section{Indications}

The lesion to be curetted must be more friable than the skin in which it arises. Indications are listed in Table 1. For all these lesions, cure rates of up to $95 \%$ can be expected. 6,9

\section{Contraindications}

Curettage should not be used for high-risk lesions because of recurrence rates of up to $27 \% .^{10,11}$ Contraindications are listed in Table 2.

Curettes range from a circular to oval outline, but some have a fenestration. ${ }^{12}$ They have an edge but are not sharp, as opposed to a scalpel. Sizes used include diameters of $1 \mathrm{~mm}, 2 \mathrm{~mm}, 4 \mathrm{~mm}$ and $7 \mathrm{~mm}$. Curettes of $4 \mathrm{~mm}$ diameter are most commonly used. ${ }^{12}$

Curettage is usually performed in conjunction with cautery. The term 'cautery' here refers to any form of heat-induced haemostasis (ie hot wire, electrodessication and electrofulguration). Most curettage and cautery is performed 
with a hyfrecator for electrodessication or fulguration. Electrocautery involves direct thermal injury to the tissue, whereas hyfrecators use electrical current to damage and coagulate the targeted tissue. Precautions should be taken in patients with an implanted device such as a pacemaker, defibrillator, deep brain stimulator or Cochlear implant.

\section{Efficacy}

Published cure rates of curettage and cautery document excellent results. This is dependent on lesion selection and operative technique, with cure rates of at least $95 \%$ generally accepted for suitable BCCs. ${ }^{6,10}$ Cure rates are less impressive in larger BCCs (diameter $>2 \mathrm{~cm}$ ); recurrent BCCs; aggressive growth patterns (infiltrative, morphoeic, micronodular); and nose, nasolabial or periorifical lesions. ${ }^{6,9}$ Follicular/adnexal extension likely decreases cure rates. Therefore, this technique should be avoided in terminal hair-bearing skin. ${ }^{10}$

No comprehensive randomised controlled studies have compared

\section{Table 1. Indications for curettage}

\begin{tabular}{ll}
\hline Lesion subgroup & Lesion type \\
\hline Benign lesions & Condyloma acuminatum \\
\cline { 2 - 2 } & $\frac{\text { Seborrhoeic keratosis }}{\text { Pyogenic granuloma }}$ \\
\cline { 2 - 2 } & Excess granulation tissue \\
\cline { 2 - 2 } & Keratoacanthomas \\
\hline Basal cell carcinomas & Superficial and solid subtypes \\
\hline Cutaneous squamous cell carcinomas & Diameter <10 mm \\
\hline Intraepidermal carcinomas & Low-risk types only (small size, well \\
\end{tabular}

\section{Table 2. Contraindications to curettage}

\begin{tabular}{ll}
\hline Lesion subgroup & Lesion type \\
\hline Large malignant lesions & Generally diameter $>2 \mathrm{~cm}$ \\
\hline $\begin{array}{l}\text { Aggressive growth pattern/cicatricial } \\
\text { basal cell carcinomas }\end{array}$ & $\begin{array}{l}\text { Sclerosing/morphoeic, infiltrative or } \\
\text { micronodular } \\
\text { Poor response due to fibrous stroma }\end{array}$ \\
\hline Squamous cell carcinomas & Aggressive growth patterns \\
\hline
\end{tabular}

Recurrent cutaneous malignancies

Malignancies with follicular or adnexal

extension, or extension through the dermis

$\begin{array}{ll}\text { High-risk sites } & \text { 'H' zone: face, ear, embryonic fusion planes } \\ & \text { Exception: if }<3 \mathrm{~mm} \text { in diameter }\end{array}$

Very thin skin

Eyelids, lip, genitalia

High risk of penetration into subcutis

Melanocytic lesions

curettage and cautery with excision, cryotherapy or radiation approaches in the treatment of SCC and related lesions. ${ }^{6}$ It is thought to have similar efficacy. ${ }^{13}$ One case series of cutaneous SCCs treated with curettage and cautery demonstrated a $96 \%$ cure rate. ${ }^{6}$ However, this study only included low-risk lesions that were less than $2 \mathrm{~cm}$ in diameter and not deeply invasive, destructive or sclerosing. This emphasises the need for careful lesion selection. High-risk sites for SCC, in which curettage is generally avoided, include the scalp, ear, nose, eyelids, lip and non-sun exposed areas (ie perineum, sacrum, sole of the foot and mucosa), unless the SCC is very small (ie $<5 \mathrm{~mm}$ in diameter). ${ }^{6}$ SCCs arising in areas of prior radiation, thermal injury, chronic inflammation (ie chronic draining sinuses or ulcers), scar tissue or intraepidermal carcinoma are also high risk and unsuitable for curettage. ${ }^{9}$ Recurrent lesions are considered to be high risk, as are those arising in patients who are immunosuppressed.

\section{The techniques of curettage and cautery}

1. Mark out the lesion and cleanse the area with an antiseptic (non-flammable).

2. Infiltrate with local anaesthesia using plain lignocaine, as the haemostatic effect of adrenaline is not required when using cautery.

a. Scrape the lesion out using a 3-4 mm curette. Ensure adequate tension of the skin using fingers. The curette passes from the periphery to the centre of the lesion in a back-and-forth motion until normal uninvolved skin is reached. The curettage should be vigorous and in multiple different directions. A good curette is audible as it scrapes against dermis. Some literature recommends using the smaller curettes at the end to reach any small pockets of residual lesion. ${ }^{14}$ The curette delineates the tumour, as only lesional tissue will yield specimen to the instrument. This technique is preferred for superficial BCC and intraepidermal carcinoma/ Bowen's disease (Figure 1). 
b. Another method is to first shave the lesion out, and then curette the base and margins in the manner described above (Figure 2). This may be more useful for solid BCCs and keratoacanthomas. The shave may clear the lesion. A complete shave specimen allows easier histopathological differentiation of a keratoacanthoma from an SCC.

3. After curettage, apply light cautery to the wound and a 1-2 mm margin. The cautery should stop the bleeding without causing excessive charring. Excessive cauterisation increases the risk of a hypertrophic or keloid scar. ${ }^{15}$ Cautery both destroys carcinogenic tissue and provides haemostasis. ${ }^{9}$ Hyfrecation is preferred to electrocautery as it causes less significant thermal injury. Injury to underlying structures is possible, and therefore the skin should be elevated away. Ensure that there are no flammable substances on the skin and no flowing oxygen. If operating around the perineum, a moist pack over the anus is advised as methane is flammable.

4. Two or three cycles of curettage and cautery are usually performed. ${ }^{16}$

5. Aftercare varies between centres. While a dry dressing is usually applied at the end of the procedure, some leave the wound uncovered, and some apply antiseptic. Healing usually occurs within 2-4 weeks but is site dependent, with lower limb defects healing the slowest. Patients should be advised that they may shower but should not swim for at least seven days post procedure.

6. Some recent articles suggest that cautery can be avoided in suitable non-aggressive BCCs if the clinician is confident with lesion selection and technique. ${ }^{8,14}$

\section{Complications}

As with any surgical procedure, there is a risk of infection. However, this risk is low $(<1 \%)$ with curettage as the wound is not closed under tension, there is no foreign material in the wound (ie sutures) and there is no penetration into the subcutis. ${ }^{17,18}$ Haemorrhage post procedure may occur. Typically, pressure, further cautery or a suture will stop this bleeding. The resultant scar, once mature, is approximately the size of the lesion treated. As with any surgical procedure, cosmetic outcomes are variable, but results are usually satisfactory to good. Scarring varies subject to multiple factors including the size and site of the lesion, the degree of solar damage, patients' individual tendencies to scarring and pigment disturbance. In some instances, excision can result in a superior scar. Patients' attitudes to cosmetic outcomes and scarring from past procedures need to be considered when choosing a treatment option. A curettage scar can be re-excised if desired. There is a risk of hypertrophic and keloid scarring. ${ }^{19}$ The risk is greater on the anterior chest and deltoid and in patients with darker skin. ${ }^{20}$

\section{Advantages}

Curettage is easy, cost-effective, quick and highly effective. ${ }^{10}$ The equipment required is minimal. It can routinely be delivered on the same day the lesion is found and without need for a formal operating theatre. Multiple lesions can be readily treated in one appointment. Aftercare is simple. There is no need for the patient to return for suture removal. The patient does not have to restrict physical activity as much as with excision, as there is no risk of dehiscence. The procedure produces histopathology (unlike cryotherapy, radiation, photodynamic therapy or imiquimod), which largely removes the need for pre-treatment biopsy in clinically typical lesions. If the histopathology reveals a more aggressive lesion than initially diagnosed, re-excision
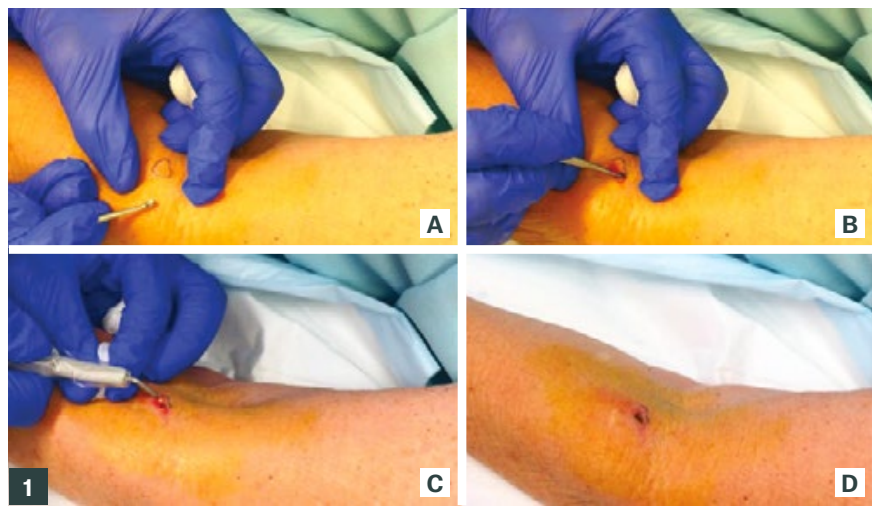

Figure 1. Curettage and cautery of a superficial basal cell carcinoma on the arm

Figure 2. Curettage and cautery of a keratoacathoma on the ankle, preceded by initial shave excision to debulk and preserve architecture for the dermatopathologist
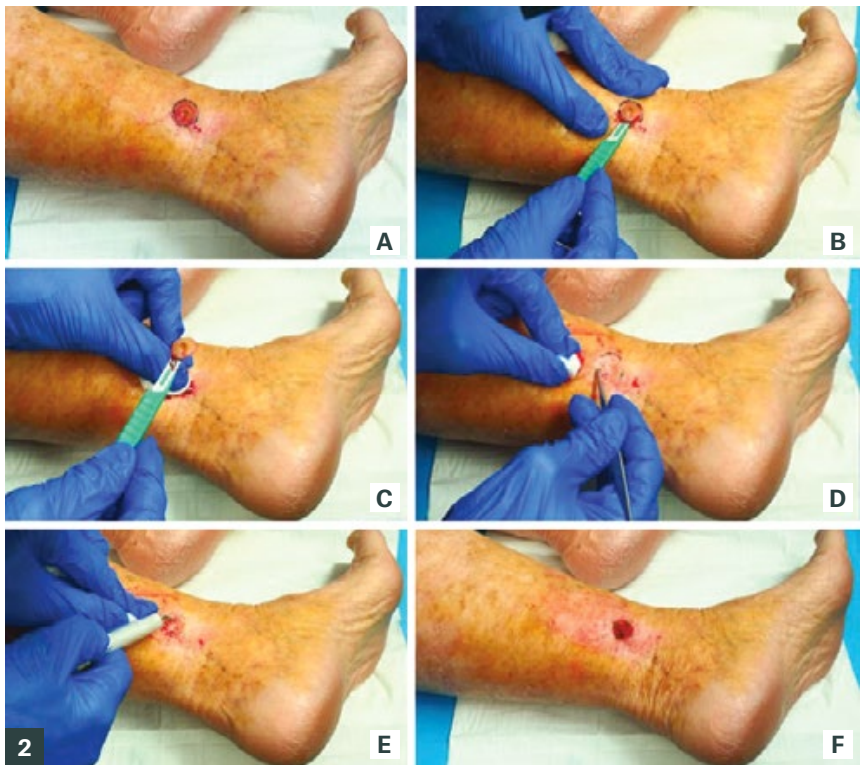
can be performed if indicated. ${ }^{6,9}$ Curettage is particularly useful for sites where healing after excision can be difficult (eg the anterior shin). The procedure can be performed with confidence on patients who are taking anticoagulant medications. Cosmetically, Silverman et al showed physician-rated cosmesis after curettage for BCC as good to excellent in $76 \%$ at one year, rising to $92 \%$ at 15 years. $^{21}$

\section{Disadvantages}

There is an open wound, but it will be small and is usually easy to look after. Healing times vary depending on patient characteristics, medications, the size and site of the lesion and operator technique. Small curettes of superficial lesions on the upper limb or trunk in an otherwise healthy individual can be expected to heal within 2-4 weeks. Larger wounds on older or infirm patients, especially on the lower limb, can take considerably longer. ${ }^{15}$ Obesity, diabetes and smoking may also prolong healing. Curettage and cautery has a narrower range of indications than excision. ${ }^{23}$ Scarring is inevitable, and hypertrophic, keloidal, atrophic, hyperpigmented and hypopigmented scars may occur. ${ }^{19}$ As with any second intention healing tissue, contracture can also occur. Post-operative pain is rarely a significant issue. ${ }^{24}$

A common concern is the lack of histopathological 'confirmation of clearance' with a curette specimen. As a curette only harvests involved tissue, specimen margins are expected to be involved. As with cryotherapy, imiquimod, photodynamic therapy or radiation, cure is dependent on lesion selection and technique rather than clear histological margins. It should be remembered that with an excision specimen, only a tiny fraction of the submitted specimen is examined.

If curettage penetrates the subcutis, suggesting tumour extension deep to the dermis, the procedure should be changed to excision.

\section{When to biopsy first}

A biopsy should be performed first:

- to confirm the clinical diagnosis and/or subtype if uncertain on clinical grounds
- for lesions in cosmetically significant sites such as the décolletage.

A shave biopsy is the best option. A punch biopsy should be avoided before curettage, as it will pass through the dermis into the subcutis. This makes the curettage unable to differentiate deep tumour extension and an iatrogenic tract. ${ }^{15}$

\section{Post-procedure scarring}

Scarring is usually minimal. ${ }^{18,25}$ This is largely dependent on the patient and site. Scarring is more likely in non-sun damaged skin and high-risk sites such as the anterior chest. ${ }^{25}$ Warning the patient about the type of scarring expected (and possible) with curettage is important. If desired, re-excision of the scar could be offered to convert the curette scar into an excisional scar.

\section{Conclusion}

Curettage and cautery is a quick, cost-effective and effective procedure when performed well for appropriate lesions. It is a very useful management option for low-risk skin malignancy.

\section{Key points}

- Given good lesion selection and operative technique, curettage is very effective in the management of low-risk skin malignancies.

- Curettage should not be used in high-risk lesions because of high recurrence rates.

- The procedure is quick and simple to perform.

- Scarring is generally minimal but dependent on the patient and site.

- With curettage, cure is not dependent on clear histopathological margins.

\footnotetext{
Authors

Daniel Mazzoni BMedSt, MD, Basic Physician Trainee, Royal Brisbane and Women's Hospital, Qld Jim Muir MBBS, FACD, FACRRM (Hon), Consultant Dermatologist, Mater Hospital, Qld; Associate Professor, University of Queensland, Qld

Competing interests: None.

Funding: None.

Provenance and peer review: Not commissioned, externally peer reviewed.

Correspondence to:

danielmazzoni24@gmail.com
}

\section{References}

1. Raasch B, Woolley T. Management of primary superficial basal cell carcinoma. Aust Fam Physician 2006;35(6):455-58.

2. Cancer Council NSW. Curettage and cautery for skin cancer. Woolloomooloo, NSW: Cancer Council NSW, 2020. Available at www. cancercouncil.com.au/skin-cancer/treatment/ curettage-and-cautery [Accessed 4 September 2020].

3. Tromovitch TA. Skin cancer; treatment by curettage and desiccation. Calif Med 1965;103(2):107-08.

4. Knox JM, Lyles TW, Shapiro EM, Martin RD. Curettage and electrodesiccation in the treatment of skin cancer. Arch Dermatol 1960;82:197-204. doi: 10.1001/archderm.1960.01580020039006.

5. Ferrara RJ. The private dermatologist and skin cancer: A clinical study of two hundred twentysix epitheliomas derived from five dermatologic practices. Arch Dermatol 1960;81:225-34. doi: 10.1001/archderm.1960.03730020061010.

6. Cancer Council Australia Keratinocyte Cancers Guideline Working Party. Clinical practice guidelines for keratinocyte cancer. Sydney, NSW: Cancer Council Australia, 2019. Available at wiki. cancer.org.au/australia/Guidelines:Keratinocyte_ carcinoma [Accessed 6 September 2020].

7. Reschly MJ, Shenefelt PD. Controversies in skin surgery: Electrodessication and curettage versus excision for low-risk, small, well-differentiated squamous cell carcinomas. J Drugs Dermatol 2010;9(7):773-76.

8. Kwasniak LA, Garcia-Zuazaga J. Basal cell carcinoma: Evidence-based medicine and review of treatment modalities. Int J Dermatol 2011;50(6):645-58. doi: 10.1111/j.13654632.2010.04826.x.

9. Divine J, Stefaniwksy L, Reddy R, et al. A comprehensive guide to the surgical management of nonmelanoma skin cancer. Curr Probl Cancer 2015;39(4):216-25. doi: 10.1016/j. currproblcancer.2015.07.001.

10. Fahradyan A, Howell AC, Wolfswinkel EM, Tsuha M, Sheth P, Wong AK. Updates on the management of non-melanoma skin cancer (NMSC). Healthcare (Basel) 2017;5(4):82. doi: 10.3390/healthcare5040082.

11. Jackson R, Laughlin S. Electrodesiccation and curettage. In: Schwartz RA, editor. Skin cancer. New York, NY: Springer, 1988; p. 292-95.

12. Marks J, Miller J. Lookingbill and Marks' principles of dermatology. 6th edn. Philadelphia, PA: Elsevier, 2019.

13. National Comprehensive Cancer Network. NCCN clinical practice guidelines in oncology; squamous cell carcinoma (V1.2017). Plymouth Meeting, PA: NCCN, 2017

14. Barlow JO, Zalla MJ, Kyle A, DiCaudo DJ, Lim KK, Yiannias JA. Treatment of basal cell carcinoma with curettage alone. J Am Acad Dermatol 2006;54(6):1039-45. doi: 10.1016/j. jaad.2006.01.041.

15. Sheridan AT, Dawber RP. Curettage, electrosurgery and skin cancer. Australas J Dermatol 2000;41(1):19-30. doi: 10.1046/j.14400960.2000.00383.x

16. Wiznia LE, Federman DG. Treatment of basal cell carcinoma in the elderly: What nondermatologists need to know. Am J Med 2016;129(7):655-60. doi: 10.1016/j.amjmed.2016.03.003.

17. Dixon AJ, Dixon MP, Askew DA, Wilkinson D. Prospective study of wound infections in dermatologic surgery in the absence of 
prophylactic antibiotics. Dermatol Surg 2006;32(6):819-26; discussion 826-27. doi: 10.1111/j.1524-4725.2006.32167.x.

18. Mitchell JC, Hardie M. Treatment of basal cell carcinoma by curettage and electrosurgery. Can Med Assoc J 1965;93(8):349-52.

19. Kopf AW, Bart RS, Schrager D, Lazar M, Popkin GL. Curettage-electrodesiccation treatment of basal cell carcinomas. Arch Dermatol 1977;113(4):439-43.

20. Betarbet U, Blalock TW. Keloids: A review of etiology, prevention, and treatment. J Clin Aesthet Dermatol 2020;13(2):33-43.

21. Silverman MK, Kopf AW, Grin CM, Bart RS Levenstein MJ. Recurrence rates of treated basal cell carcinomas. Part 2: Curettageelectrodesiccation. J Dermatol Surg Oncol 1991;17(9):720-26. doi: 10.1111/j.1524-4725.1991. tb03425.x.

22. Rodriguez-Vigil T, Vázquez-López F, Perez-Oliva N. Recurrence rates of primary basal cell carcinoma in facial risk areas treated with curettage and electrodesiccation. J Am Acad Dermatol 2007;56(1):91-95. doi: 10.1016/j.jaad.2006.07.007.

23. Telfer NR, Colver GB, Morton CA; British Association of Dermatologists. Guidelines for the management of basal cell carcinoma. $\mathrm{Br}$ Dermatol 2008;159(1):35-48. doi: 10.1111/j.13652133.2008.08666.x.

24. Neubert T, Lehmann P. Bowen's disease - A review of newer treatment options. Ther Clin Risk Manag 2008;4(5):1085-95.

25. Slemp AE, Kirschner RE. Keloids and scars: A review of keloids and scars, their pathogenesis, risk factors, and management. Curr Opin Pediatr 2006;18(4):396-402. doi: 10.1097/01. mop.0000236389.41462.ef. 